\title{
AFINAL, QUAL É O PAPEL DO COSTUREIRO? DA IMAGEM DO REI AOS RETRATOS DE RUI SPOHR
}

\author{
WHAT IS THE ROLE OF THE COUTURIER AFTER ALL? \\ FROM THE IMAGE OF THE KING TO THE PORTRAITS OF RUI SPOHR
}

\section{Renata Fratton Noronha'}

Recebido em: 25 de maio de 2017

Aprovado em: 30 de junho de 2017

Sistema de Avaliação: Double Blind Review

RPR | a. 14 | v. 2 | p. 113-130 | jul./dez. 2017

\section{RESUMO}

Pretendo compreender como surge o costureiro, de que forma passa a atuar como árbitro da moda. Parto do pressuposto que, após a Revolução Francesa, o costureiro passa a ocupar o lugar do rei: deixam de existir as leis suntuárias e entram e cena as coleções de outono e inverno.Se o rei se utiliza do cerimonial e da etiqueta para potencializar sua imagem soberana, o costureiro também constrói-se, inventa-se. Por isso, proponho uma análise para a construção que o costureiro Rui Spohr faz de si a partir de alguns de seus retratos, imagens representativa de sua atuação em um campo social e simbólico, relacionado ao universo da moda e suas dinâmicas.

Palavras-chave: Moda. Imagem. Cultura Visual.

\section{ABSTRACT}

This article investigates how the couturer beame a kind of arbiter, who determines what is beautiful, what is elegant, what is fashion. After the French Revolution, the couturier occupies the king's place. The sumptuary laws cease to exist and the autumn and winter collections take place.. If the king uses ceremonial and etiquette to enhance his sovereign image, the couturier also invents himself. I tpropose a look at the construction-or invention-of Rui Spohr using some of his portraits, images that represent the social na symbolical fashion environment.

Keywords: Fashion. Image. Visual Culture.

\section{INTRODUÇÃO}

\footnotetext{
- Depois das blogueiras o estilista acabou!, sentenciou alguém na sala.

- As marcas pagam uma fortuna para elas postarem uma foto! São elas as donas da moda!, a mesma voz concluiu.

Era uma tarde de visita rápida, peguei a conversa ao acaso. Sobre a mesa havia uma revista espanhola, com os últimos desfiles de alta-costura. Karl Lagerfeld posava ao lado de uma menina de vestido cor de rosa, que lembrava o de Joan Crawford no filme Letty Linton.

- Quem é a nova égerie?, perguntou Rui.

- Filha daquela cantora francesa, a Vanessa Paradis e do ator Johnny Dep.

- Ahn..., respondeu com ar de pouco interesse. Mas é tão magrinha, não tem nem corpo ainda. Como pode usar Chanel? ${ }^{2}$
}

\footnotetext{
${ }^{1}$ Doutoranda em História (Pontifícia Universidade Católica do Rio Grande do Sul/Brasil). Professora na Faculdade Senac (Porto Alegre/Brasil). E-mail: ffratton@gmail.com.

${ }^{2}$ A referida conversa aconteceu no início de março de 2017, quando da preparação de um evento em comemoração ao aniversário de 79 anos Dóris Spohr e também do Dia Internacional da Mulher, já que Dóris nasceu em 08 de março.
} 
Karl Lagerfeld havia encerrado o último desfile de alta-costura da Chanel ao lado de Lily-Rose Depp que, com seu jeito adolescente, garante uma imagem de leveza e frescor aos tradicionais códigos da marca. Há ainda certa continuidade, a jovem ocupa o posto que foi de sua mãe, Vanessa Paradis, que aos 19 anos havia se tornado a imagem do perfume Chanel $\mathrm{N}^{\circ}$ 5. Essa espécie de perpetuação de juventude, parece se estender ao costureiro octogenário, que conduz Lily-Rose pela passarela.

Rui Spohr, costureiro gaúcho, gosta de dizer que possivelmente cruzou com o jovem Karl, ou ainda com Yves Saint-Laurent- antes que se tornasse o sucessor de Dior- nos corredores da escola da Chambre Syndicalle, onde estudou no início da década de 1950. No ano seguinte ao seu ingresso, Lagerfeld e Yves sagraram-se vencedores do Concours de la Laine, momento maior de projeção aos alunos, já que aos vencedores era dada a oportunidade de confeccionar seus modelos e mostra-los em desfile, com cobertura da mídia, grande exposição. ${ }^{3}$

Se Saint-Laurent fez sucesso sob a própria assinatura, a Lagerfeld coube associar seu talento a marcas que já detinham algum prestigio. A companhia de pessoas mais jovens também parece ter sido uma estratégia. No caso da Chanel, que tratou de mitificar Gabrielle - ou Coco sua fundadora- o peso da tradição da marca, associada à juventude de Lily-Rose, parecem situar Karl Lagerlfeld justamente no presente - o tempo onde atua.

Mas, em tempos de selfies, onde as mídias sociais se transformam em território poderoso de visibilidade, afinal, qual é o papel do costureiro?

Neste artigo, não pretendo discutir o futuro da moda ou as estratégias atuais das grandes marcas para se manterem vivas-tanto comercialmente quanto no imaginário social. Esta seria uma tarefa bastante árdua em um momento de crises de todas as ordens -que alteram também as formas de (a) parecer, consumir- tanto no sentido do que se compra, quanto do como se vende, ou ainda os meios por onde circulam as mais diferentes estratégias de visibilidade voltadas para a publicidade.

A moda é um fenômeno que se faz de imagens- que acaba por se transformar em imagem também. Neste sentido, o criador de moda pode ser compreendido como uma espécie de colecionador destas imagens, que povoam sua memória e, sobrepostas, rearranjadas são capazes de dar visibilidade a transformações de hábitos, usos e costumes que se modificam de acordo com as variações da cultura em que se inscrevem.

Durante muito tempo, Lagerlfed foi chamado de o kaiser, o imperador da moda. O título não demonstra apenas nobreza, mas soberania, ou seja, o costureiro com seu quê de gênio, seu olhar apurado, traço firme transformado em desenho, seria aquele a quem foi dado o dom de traduzir o espírito de seu tempo em roupas, transformando, especialmente, os corpos das mulheres.

Se o rei se utiliza do cerimonial e da etiqueta para potencializar sua imagem soberana, o costureiro também se constrói, inventa-se. Por isso, proponho ainda um olhar para a construção - ou invenção - de Rui Spohr a partir de alguns de seus retratos, uma forma de dar atenção a gestos e marcas que ora se reptem, ora se sobrepõem e, na maioria das vezes, escapam às palavras que este mesmo escolhe para traduzir as memórias que contam a sua história de vida.

\footnotetext{
3 O referido concurso é o ponto de partida para a autora Alicia Drake desenhar uma espécie de retrato cruzado dos dois nomes importantes da moda do século XX. Sobre Yves Saint-Laurent, comenta sua relação com as drogas e a importância de seu relacionamento com Pierre Berger. Sobre Lagerfeld, a busca pela imagem jovem que se reforça a partir da companhia de pessoas igualmente jovens. DRAKE, Alicia. Beautiful People. Saint Laurent, Lagerfeld: splendeurs et misères de la mode. Paris: Folio, 2010.
} 


\title{
2 O REI, SOBERANO DO (A)PARECER
}

\begin{abstract}
Se um homem imparcial repassasse uma a uma todas as modas francesas desde a origem da França até os dias de hoje, nada encontraria de chocante nem mesmo de surpreendente. As transições seriam, nesse caso, tão graduais quanto o são na escala do mundo animal. Nenhuma lacuna e, portanto, nenhuma razão para surpresa. E, se a vinheta que representa cada época, ele juntasse o pensamento filosófico que mais a ocupou ou agitou, pensamento cuja lembrança a vinheta inevitavelmente sugere, veria que profunda harmonia rege todos os elementos da história e que, até mesmo nos séculos que nos pareceu ser os mais monstruosos e loucos, o imortal apetite pelo belo sempre encontrou sua satisfação (BAUDELAIRE, Charles, 2010, p.32).
\end{abstract}

Nesta visão evolutiva de Charles Baudelaire sobre a moda, o vestir manifesta a atualidade de seu tempo não apenas como uma tradução tangível, que se dá através daquilo que envolve o corpo, mas, de certa forma, como uma espécie de antecipação ${ }^{4}$, sinalização do pensamento ainda não expresso, manifestação de um devir onde satisfação pelo belo está relacionada com as formas de sociabilidade, do simbólico e do imaginário. A moda é a modernidade, implicada em "extrair o eterno do transitório" (IDEM, p.35)

Apesar de não afetar todos os tempos e todas as civilizações, a moda imprime novo ritmo às sociedades. Seu surgimento, no final da Idade Média, está relacionado ao desenvolvimento do comércio, seus intercâmbios e o consequente desenvolvimento das cidades. Especialmente na sociedade de corte, a partir do Renascimento, que se estabelece uma espécie de fábrica de padrões de vestuário e normas de etiqueta. Inegável é o papel de Louis XIV, o rei Sol, que fez de Versalhes seu território de atuação- e também de encenação.

Ao analisar a sociedade de corte e seu papel na organização de um conjunto de relações sociais durante o Antigo Regime, Norbert Elias (2001) demonstra que a submissão da corte é o mecanismo principal da perpetuação do poder do soberano. Tal submissão se dá a partir do controle fiscal militar e de elaboradas normas de etiqueta. Nesta espécie de jogo onde manipulação de certos códigos representa a detenção do poder, o rei também se submete às suas regras como forma de manutenção de sua figuratividade absoluta. Para que haja hierarquia, o soberano estabelece com sua corte uma relação de interdependência, ou seja, sendo o rei o primeiro entre os nobres, a ruína da nobreza significaria também a ruína do rei.

Dessa forma, a etiqueta e seus rituais tornam visíveis a necessidade de os nobres formarem uma elite assim como convém a uma necessidade de dominação do rei, que se constituem como instrumento duplo, de distanciamento e também de ação.

Ao cerimonial associa-se também o vestuário do rei e da nobreza: como observa Philippe Perrot (1981), o vestuário, no Antigo Regime, classificava seu portador de acordo com uma ordem rigorosa, onde o uso de determinadas cores e formas se dá de maneira restrita sendo alvo de leis suntuárias- ou ordonnances vestimentaires- que funcionam como instrumentos de regulação política, social e econômica, onde à nobreza fica assegurada a exclusividade ao vestuário luxuoso que irá distingui-la dos demais grupos. Ainda segundo Perrot, durante o reinado de Louis XIV, o vestir é minunciosamente regulado: a condição social, a estação do ano e ocasião podem determinar desde a largura e tipo de enfeites ao formato e material dos botões, por exemplo. As competições e rivalidades se evidenciam no vestir da sociedade de corte uma vez que "o parecer condiciona o ser", configurando-se em um desafio

\footnotetext{
${ }^{4} \mathrm{~A}$ ideia de antecipação também é cara ao autor Fréderic Monneyron. Em suas palavras, «Je voudrais em effet m'enployer à esquisser que, non seulement le vêtement ne suit as l'histoire, mais, position quelque peu iconoclaste,qu'il la prècede; qui bien de nos comportements' la demarche, le tempo, le rythme des gestes sons sans nul doutes determinés par lui». MONNEYRON, Fréderic. La frivolité essentielle. Paris: Ed. Puf, 2008.
} 
proposto entre e para os seus membros, que acaba por servir como força afirmativa ao poder absoluto do rei.

Ao definir a corte francesa como uma "fábrica" de regras de etiqueta da época moderna, Isabelle Paresys (2012) observa essa dinâmica de "consumo de prestígio", sistematizada por Louis XIV que acaba por se transformar numa espécie de ethos da nobreza, que regulamenta suas despesas com o vestuário a partir das exigências da posição que precisa manter em relação ao (a) parecer na corte. ${ }^{5}$

O luxo, os materiais preciosos, as formas e acessórios complementares que devem estar adequados aos espaços, ocasião e hierarquia, servem à materialidade dos corpos cuja anatomia, modelada pelo vestuário ganha especial eloquência. Na corte, mais do que e qualquer outro espaço, o corpo vestido é uma representação espetacular a partir de sua própria silhueta: vestir-se de determinada forma constitui-se em uma norma, perfeitamente incorporada pelo soberano e seus cortesãos, ou seja, da mesma forma que a etiqueta rege a vida dentro do espaço da corte assim como o cerimonial, as regras relativas ao vestuário são a expressão da hierarquia da corte.

Figura de poder cuidadosamente construída, Louis XIV, na visão de Peter Burke (1994), controla os rituais como forma de manipulação simbólica do poder e a etiqueta e seus rituais se tornam fundamentais na fabricação de sua imagem pública. A propagação das imagens do rei- também inserida no imaginário ainda através da literatura e dos meios orais- ampliavam sua visibilidade, funcionando como uma espécie de propaganda e servindo ainda de modelos a outros soberanos.

A fabricação do rei se faz a partir da dramaticidade de seu cotidiano, onde tudo é controlado, encenado. O corpo do rei fica totalmente submetido ao olhar da corte, cada ação, cada gesto funciona como estratégia de manutenção de prestigio, algo que poderá lhe subsistir, pois se o corpo físico do soberano não é eterno, o contrário acontece com sua imagem:

Os atos de levantar de manhã e ir para a cama de noite foram transformados nas crimônias do lever e do coucher- sendo a primeira dividida em duas etapas, o petit lever, menos formal, e o grand lever, mais formal. As refeições do rei também foram ritualizdas (...) Essas refeições eram encenações perante uma audiência. Era uma honra ser autorizado ver o rei comer, honra maior receber uma palavra sua durante a refeição, honra suprema ser convidado a servi-lo ou comer com ele.

(...).

Havia normas formais para a participação nesse espetáculo- quem tinha direito de ver o rei, a que horas e em que partes da corte, se tal pessoa podia se sentar em uma cadeira ou em um tamborete [tamboret] ou tinha que permanecer de pé. A vida diária do rei compunha-se de ações que não eram simplesmente recorrentes, mas carregadas de sentido simbólico, porque eram desempenhadas em público por um ator cuja pessoa era sagrada, Luís esteve no palco durante quase toda sua vida vigil (BURKE, 1994, p.99-101).

Sobre as questões de etiqueta e de boas maneiras, Norbert Elias diz que os mecanismos de distinção, controle do corpo e das emoções, ao serem corretamente empregados, garantem a "civilização" dos modos e a consequente manutenção de status - ou de poder:

\footnotetext{
${ }^{5}$ Para a autora, "Louis XIV fut accusé par Saint Simon, au début du XVIIème siècle, en avoir tourné n " maxim politique »le goût de "l a splendeur, la magnificence, la profusion », épuisant par la des courtisans 'en mettant le luxe en [...] necessité » réduisant ainsi peu à peu « tout le monde à dependre entièrement des ses bienfaits pour subsister». La bienveillence du roi est en effet ne chance essentielle dont dispose la noblesse d'éppée pour échapper à l'appauvrissement provoqué par ses dépenses pour paraître à la cour ». PARESYS, Isabelle. La cour de France, fabrique de normes vestimentaires à l'époque moderne. IN : La Fabrique de la norme. Veronique Beaulande-Barraud, Julie Claustre et Elza Marmursztejn. Presses Universiteraires de Rennes, 2012.
} 
O comportamento social e a expressão de emoções passaram de uma forma e padrão que não eram um ponto de partida, que não podiam em sentido absoluto e indiferenciado ser designados de 'incivil', para o nosso, que denotamos com a palavra ‘civilizado'. A ‘civilização' que estamos acostumados a considerar como uma posse que aparentemente nos chega pronta e acabada, sem que perguntemos como viemos a possui-a, é um processo ou parte de um processo em que nós mesmos estamos envolvidos. Todas as características distintivas que lhe atribuímos-a existência de maquinaria, descobertas cientificas, formas de Estado, ou o que quer que sejaatestam a existência de uma estrutura particular de relações humanas, de uma estrutura social peculiar, e de correspondentes formas de comportamento (ELIAS, 2011, p.70).

Para Freud "a palavra 'civilização' designa a inteira soma das realizações e instituições que afastam a nossa vida daquela de nossos antepassados animais, e que servem para dois fins: a proteção do homem contra natureza e a regulamentação do vínculo dos homens entre si." (FREUD, 2010, p.33). Assim ao "civilizado" tem importância aquilo sem utilidade aparente, mas que entra nas reivindicações do campo da cultura, como a beleza, a limpeza e a ordem. Desta forma, transformam-se em exigências que coincidem com a sublimação do instinto:

[...] traço bastante saliente na evolução cultural, ela torna possível que atividades psíquicas mais elevadas, cientificas, artísticas, ideológicas, tenham papel tão significativo na vida civilizada. Cedendo à primeira impressão, seriamos tentados a dizer que a sublimação é o destino imposto ao instinto pela civilização (IDEM, p.40).

Podemos pensar que a submissão à etiqueta, a valorização do cerimonial e a imposição de um modo de vida onde "o parecer condiciona o ser" ajudam a construir o corpo civilizado, portanto, vestido. As roupas ao moldar, deformar a sua forma frágil, mais do que escondê-lo, revelá-lo, o constroem a partir de imposições, exigências que, na sociedade de corte, são representadas pelas leis suntuárias.

Após a Revolução Francesa, o que era norma passa a ser direito, uma vez que os indivíduos se tornam livres para adotar o vestuário que lhe for conveniente- de acordo com o seu gênero ${ }^{6}$.

Manuais de etiqueta e civilidade passam a determinar uma espécie de pedagogia do savoir-vivre, testemunhando as demandas da burguesia em ascensão por sinais de pertencimento que reforçar seu sucesso financeiro e legitimar uma nova posição social.

$\mathrm{Na}$ sociedade industrial, as roupas se tornam, gradualmente mais acessíveis em virtude da evolução dos processos de produção e circulação de mercadorias. Nesse sistema de consumo-que chega ao seu sentido moderno- a distinção não é apenas o "ter", determinado pelo poder aquisitivo, mas "o que ter" ou o saber comprar de forma a confirmar uma imagem construída a partir do gerenciamento da aparência. Para isso, é importante se estar à vontade com as regras de etiqueta assim como fazer uso adequado das roupas, ou seja, dominar também os códigos da moda.

\section{O NASCIMENTO DO COSTUREIRO}

Ao observar as dinâmicas que se estabelecem no século XIX, o historiador Philippe Perrot observa que "a boa conduta vestimentar" é perpassada por valores como a limpeza, a simplicidade e a correção, suscitando novos discursos sobre novas condutas que atestam sua especificidade cultural ${ }^{7}$. O cuidado e

\footnotetext{
${ }^{6}$ De acordo com o decreto de 29 de outubro de 1793, "Nenhuma pessoa, não importando o seu sexo, poderá forçar nenhum cidadão ou cidadã a se vestir de uma maneira particular, sob pena de ser considerado e tratado como suspeito e perseguido como perturbador da ordem pública; cada um é livre para portar uma indumentária particular ou adequá-la à maneira que lhe convier" Tradução nossa. PERROT, Le dessus et le dessous de la bourgeoisie. Paris: Ed Fayard, 1981, p.38.

${ }^{7}$ No original: "Issues, comme la distinction, des stratégies sociales nouvelles, la propeté, la simplicité et la correction suscitent des discours nouveaux, des conduites nouvelles qui attestent de leur spécificité historique et culturelle. La propeté vestimentaire ( et non pas corporelle, encore rudimentaire) pend, avec et comme l'essor de l'hygiene, une extension formidable au XIXeme
} 
a limpeza das roupas - e a não apenas do corpo-reforçam o controle sobre todo o conjunto da aparência.

O psicanalista inglês John Carl Flügel foi o pioneiro ao desenvolver uma análise que levou em conta as teorias freudianas, construindo uma relação com a moda e o vestuário. Em estudo publicado em 1930, Flügel analisa as três principais funções do vestir: o adorno ou enfeite, a proteção e o pudor.

Ao analisar a natureza psicológica das funções de decoração e pudor, o psicanalista chama a atenção para uma visão filogenética e outra ontogenética: na filogenética, a partir de uma visão antropológica, o adorno seria a primeira motivação do vestir e o pudor seria a consequência de hábitos adquiridos, motivos de embelezamento e a proteção seria algo pouco importante nas primeiras fases do desenvolvimento da roupa. Já em uma abordagem ontogenética, a visão seria inversa: neste sentido, às crianças seriam impostos hábitos que correspondem a ideais de higiene, moral e estética, mais do que às suas próprias necessidades e desejos.

A satisfação da criança em seu estado de nudez seria uma fonte de prazer, de caráter auto erótico e também narcísico. Uma forma de suprimir este prazer seria substituir o interesse primitivo pelo corpo nu pelo interesse pelas próprias roupas, onde os meios empregados para combater e suprimir satisfações primitivas acabam por se tornar os meios de satisfazer os mesmos instintos. Para o psicanalista inglês:

As roupas constituem uma espécie de ambiente artificial que o homem interpõe a seu próprio corpo e seu meio. Esse ambiente - embora tenhamos o poder de constituí-lo e de mudá-lo conforme a nossa vontade - é tão constantemente presente e se torna tão natural, que não inspira em geral a curiosidade verdadeira. E isso devido a esse meio curioso - meio que possui ao mesmo tempo as qualidades de pele exteriorizada, com suas funções de higiene e de erotismo; de casa ambulante; com suas funções protetoras, decorativas e pudicas (FLUGEL, 2008, p.22).

Voltando às imagens da vida moderna de Baudelaire,

A moda deve, pois, ser considerada como um sintoma do gosto do ideal que sobrenada no cérebro humano por sobre tudo que a vida natural aí acumula de grosseiro, de terrestre, de imundo, como uma deformação sublime da natureza, ou melhor, como uma tentativa permanente e continuada de reforma da natureza (BAUDELAIRE, 2010, p.71).

Desta forma, o cuidado e a limpeza das roupas - e a não apenas do corpo - reforçam o controle sobre todo o conjunto da aparência, reforçando as sobre o vestir como meio de sublimação do instinto, fuga da animalidade e o estabelecimento de vínculos, como sugere Flugel a partir das ideias de Freud. Se não há mais ordem e sim direito no que diz respeito às escolhas do vestir, a encenação social exige não apenas o domínio do corpo no controle de seus modos e gestos, mas uma espécie de pedagogia relativa ao decoro e à etiqueta. "O que vestir" e "como vestir" se tornam traços visíveis do lugar de cada um ocupa na sociedade que emerge após a Revolução.

Como observa Diana Crane, nas sociedades do século XIX, o vínculo a determinada classe social constituía um dos aspectos mais importantes da identidade social e as diferenças nos usos de vestuário indicavam a natureza das relações entre as classes. Na classe operária, por exemplo, as roupas representavam parte importante dos bens de uma família. Dessa forma, um terno masculino deveria servir a uma variedade de usos, durante um longo período de tempo, assim como as mulheres jovens preparavam seus enxovais também com trajes e roupas intimas que deveriam durar décadas.

siècle, où le blanchissage du lange, en pariculière, joue dans ses raisons prophylactiques et somptuaires un rôle sans précédant. IDEM, p.227-228. 
Muitas abordagens se dão sob o ponto de vista do consumo, ou ainda a partir de certa "luta visual entre classes," onde imperam gostos e formas de distinção--que tendem a sofrer um processo de imitação e, por isso modificam-se constantemente. O economista Thorstein Veblen analisa a estrutura econômica de sua época enfatizando os usos e os costumes como elementos explicativos da atividade econômica, especialmente, das classes mais favorecidas. Já para o sociólogo alemão Georg Simmel, a moda expressa o caráter de dualidade da natureza humana, uma vez que o homem, imerso no todo social, dele tenta se diferenciar, libertar-se, isolar-se, porém sem nunca poder abandoná-lo. Sua teoria relacionará as mudanças da moda com um processo de imitação entre classes sociais em que os grupos sociais inferiores tentarão adotar o gosto das elites. Neste modelo, se parte do pressuposto que a moda é adotada pelas classes altas e, a partir disso, pelos grupos de status inferior, desencadeando um processo de contágio social.

Neste novo estilo de vida marcado pelo consumo, "toda propriedade é uma ampliação da personalidade". Portanto, as roupas como bem de consumo, obedecem a mesma lógica e acabam por demarcar não apenas gênero e classe social: “'criam' comportamentos por sua capacidade de impor identidades sociais e permitir que as pessoas afirmem identidades sociais latentes" (CRANE, 2009, p.22).

Apesar de Londres ser a cidade símbolo da revolução industrial, ponto de partida para Marx escrever seu manifesto - que se inicia justamente a partir de seu casaco, ou seja, peça de vestuário importante que, por uma questão de etiqueta determina se poderá ou não entrar na biblioteca para realizar sua pesquisa ou poderá ainda ser penhorado para que possa comprar papel para que possa escrever seu texto sobre o capital (STALYBRASS, 2004) será Paris, reconstruída por Napoleão III seguindo o projeto arquitetônico de Haussmann, a capital do século XIX.

Foi em Paris que o inglês Charles Worth se instalou de maneira definitiva, transformando-se no precursor da alta-costura e que irá revolucionar a forma de produção e comercialização de produtos ligados ao vestuário, que dará novo prestígio à figura do costureiro.

O gesto realizado por Worth corresponde à emancipação do costureiro em seu papel de simples artesão, ao se tornar um artista que deixa de ser subordinado à sua clientela, para "criar" modelos com base em sua própria subjetividade, os quais carregarão a marca da sua assinatura. Se a separação de artes e ofícios, no século XVIII, insere a costura na última categoria, o surgimento da alta-costura determina que a moda aspire a ser reconhecida como arte, pelo menos, no que diz respeito ao processo criativo de elaboração de novos produtos (SVENDERSEN, 2010).

Para o filósofo Gilles Lipovetsky,

A vocação criadora do costureiro, que define a própria Alta-Costura, é inseparável e uma nova lógica no funcionamento da moda: realizou-se uma mutação organizacional que assinala a entrada da moda na era da produção moderna. Até Worth, o alfaiate, a costureira, a comerciante de modas jamais deixaram de trabalhar em ligação direta com a cliente; é de comum acordo que elaboram a toalete, a elegante fazendo valer seu gosto e suas preferências, orientando o trabalho dos profissionais da moda(...)Comparado a este dispositivo artesanal, o gesto de Worth é crucial: equivale a destruição da secular lógica de subordinação (...) Essa passagem brusca indica a incontestável novidade histórica da Alta-Costura: de uma época em que a cliente coopera com a costureira a partir de um modelo em suma fixo, passou-se a uma era em que o vestuário é concebido, inventado de ponta a ponta pelo profissional em função de sua 'inspiração' e de seu gosto (LIPOVETSKY, 2009, p.106-107).

Porém, é preciso lembrar que, Charles Worth, ao chegar a Paris, havia sido funcionário da Gagelin, prestigiosa maison de nouveautés francesa. Chez Gagelin, Worth adquiriu experiência diversificada sobre o universo dos tecidos e do comércio de moda. Como tinha formação em alfaiataria, 
em 1850, tornou-se o responsável pelo departamento de confecção de vestidos. Esta posição privilegiada foi definitiva a carreira que ainda estava por vir: tinha acesso rápidos a informações, contato com fornecedores e também passou a ter proximidade com as modistas francesas, extremamente bem preparadas para os trabalhos de costura (RUBIO, 2010)

A especialista Françoise Tétard-Vittu (1992) define Worth como um especialista de vendas que, ao associar-se com Gustave Bobergh e dar início aos seus negócios na capital francesa passa a oferecer vestidos que, muito possivelmente, assemelham-se aos modelos chamados "à disposition", ou seja preparados pelas fábricas. Para Tètard-Vittu, o segredo do sucesso de Worth se deve ao fato de ter se voltado a uma clientela estrangeira. E mais: os modelos feitos para a exportação, carregam sua etiqueta, forma de autenticá-los como "verdadeiros vestidos de Paris". Worth utiliza ainda uma outra inovação da confecção que consiste na reprodução de moldes de costura. Modelos Worth podem ser copiados,a partir de 1866 de jornal Le Printemps ou, em 1867 da Harper's Bazar. ${ }^{8}$

Para Nancy Troy (2003), a habilidade em desenvolver uma roupa do início ao fim- desde a definição do modelo até a escolha de materiais e ornamentos- o permitiram controlar todas as etapas do processo de confecção, podendo dedicar-se a cada etapa de forma minuciosa sendo, ainda, capaz de distribuir comercialmente suas criações na França e no exterior. Por ter controle dos processos de criação, produção e distribuição de suas criações, Worth foi capaz de ditar a moda durante o último quarto do século XIX. Soube também cobrar por isso, uma vez que para sua clientela abastada, não bastava vestir Worth, era necessário que o modelo luxuoso- e caro! ${ }^{9}$

Rei de seu tempo, o costureiro determina as regras do cerimonial de produção da roupa: não é o seu corpo mas sua capacidade de arranjar cores e formas que passa a estabelecer uma relação de interdependência com a clientela abastada. A assinatura do costureiro estabelece a relação de proximidade, legitima o bom gosto, o prestígio financeiro e, consequentemente, a posição social privilegiada.

Se Louis XIV continuou a inspirar, com suas estratégias de construção de uma imagem que se dá pelo cerimonial, pela etiqueta, pela disputa de códigos, também Charles Worth abre um caminho: a moda francesa passou a ter ampla influência internacional e Paris seu centro irradiador. Como observa Diana Crane, este prestígio consolida o savoir-faire, ou normas e valores compartilhados, onde as técnicas são transmitidas como herança:

A maioria dos modistas franceses iniciava sua carreira como aprendizes na casa de criadores estabelecidos. Entre os franceses que estabeleceram maisons no final do século XIX para o começo do XX, havia uma ampla rede de mestres e aprendizes que interligava a maior parte das principais casas a muitas das menores. Jovens criadores começavam suas carreiras nas casas dos já estabelecidos. O resultado era um grupo relativamente coeso, com normas e valores compartilhados, o que favorecia a difusão e aceitação de novas tendências. A natureza da socialização estabelecida pelos modistas franceses contribuiu para aumentar o sucesso e o prestígio da profissão de costureiro no século XX (CRANE, 2009, p.279).

Dessa forma, Paul Poiret trabalhou na maison Worth, Pierre Cardin trabalhou com Dior, Yves Saint-Laurent o sucedeu. Se, ao contrário do que acontece com os reis, a alta-costura não deixa herdeiros, assim como no universo da arte terá seus mestres.

\footnotetext{
8 TÈTARD-VITTU, Françoise. La naissance du couturier et du modeliste IN : Au paradis des dames. Catálogo de exposiçao. Paris Musées, 1992.

${ }^{9}$ TROY, Nancy. Couture Culture. A Study in modern art and fashion. Massachustes: The MIT press., 2003, p. 19-21.
} 


\section{A INVENÇÃO DE RUI SPOHR}

Flavio Spohr nasceu em 1929 em Novo Hamburgo, cidade marcada pela imigração alemã, localizada no Vale dos Sinos- não muito distante de Porto Alegre. Segundo filho de uma família tradicional, católica- enquanto grande parte da comunidade da região professa a religião protestantequando adolescente não vê encanto no trabalho repetitivo na fábrica de calçados do pai, prefere as páginas da revista O Cruzeiro, as fotografias de Evita Peron vestindo Christian Dior. Fez curso de Contabilidade por exigência do pai, condição para que pudesse estudar Belas Artes. Inspirado pelas revistas, apaixonou-se pela moda e resolve dela fazer seu ofício: começou escrevendo para o jornal local depois organiza um desfile- sem sequer ter visto um!- e, finalmente, partiu para Paris, em 1953- quando a Europa ainda se recuperava da guerra.

E assim Flavio se transformou em Rui. E sua história, muitas vezes repetida, foi deixando de ser apenas sua, incorporou outras memórias, ganhou novos agentes e outros olhares.

Vasculhar essas memórias é perceber onde Rui e Flavio se encontram: fragmentos de entrevistas, fotografias, trechos de conversas ajudam compor arqueologia desta Roma particular onde nada que uma vez aconteceu tenha se perdido.

\section{CADA VEZ MENOS FLAVIO, CADA VEZ MAIS RUI}

No ano de 1995, aos 65 anos, Rui completou 40 anos de carreira. A comemoração da data resultou na exposição fotográfica "Rui, estilo em fotos". O registro mais comentado foi o de Luiz Eduardo Achutti, que convidou o costureiro a posar nu. E é praticamente em torno desta fotografia que se dá o perfil traçado pela jornalista Mariana Kalil para o Caderno Donna, do jornal Zero Hora do dia 10 de setembro do mesmo ano.

"O Flavio que criou o Rui", chama a manchete para em seguida dizer que "aos 65 anos, o estilista comemora 40 de carreira e revela que conseguiu unir os dois personagens de sua vida".

À jornalista relata o trabalho repetitivo que consistia em cortar couro na fábrica de calçados do pai: “'Aquele trabalho era tão mecânico que me deixava em pânico por não estimular a minha criatividade e imaginação"”. E ainda a chegada da edição semanal da revista O Cruzeiro:

(...) o menino corria para o pátio e examinava com atenção cada página. Em uma das edições, Flávio encantou-se com um vestido usado peça então primeira-dama argentina. Ao olhar para o pedaço de couro á sua frente, percebeu que o design que estava criando era exatamente igual ao traje de Evita, um modelo de Dior: 'Então passei a procurar em cada pedaço de couro que eu cortava uma inspiração para criar um vestido'. Naquele momento, sem perceber, Flavio começava a fazer moda. O menino tornava-se cada vez menos Flávio e cada vez mais Rui. ${ }^{10}$

O costureiro comenta o desejo de escrever um livro contando sua história- o que se efetiva em 1997-dá mais alguns detalhes sobre a exposição comemorativa e a fotografia polêmica onde apareceria nu e o texto se encerra com o enlace entre Flávio e Rui:

${ }^{10}$ KALIL, Mariana. Caderno Donna. Zero Hora, 10 de setembro de 1995. 
Quatro meses atrás, Rui participou de um curso de biodança em São Francisco de Paula. Durante muito tempo o costureiro ouviu que Rui havia matado Flávio. 'As pessoas diziam que o Rui era sucesso e que o Flavio não era nada'.Em uma das aulas, os alunos tinham que dançar em duplas. Rui distraiu-se e ficou só. No embalo da música, começou a dançar consigo mesmo, acariciando seu próprio corpo, seu cabelo. ' Fiz em mim o que as duplas faziam entre si', diz. Com a voz embargada, Rui baixa os olhos, aperta as mãos, enrubesce. Atrás dos óculos, uma lágrima ameaça cair. 'Pela primeira vez depois de todos esses anos, fui integrando o Rui ao Flávio', afirma. ' E a concorrência finalmente chegou ao fim. ${ }^{11}$

Pode-se dizer que é o encontro de Rui com Flavio que norteia o texto autobiográfico "Memórias Alinhavadas", escrito em parceria com Beatriz Viegas-Faria, lançado em 1997. A narrativa em primeira pessoa é apresentada de forma não linear que conduz, inicialmente, à sua experiência como estudante em Paris, seguindo-se a chegada a Porto Alegre, com a construção de seu espaço profissional, para, somente então, evocar fatos de sua infância vividos em sua cidade natal, Novo Hamburgo. O livro conta ainda episódios importantes e inusitados- como a participação nos desfiles promovidos pela Rhodia na década de 1960 ou ainda a história da noiva que dizia "o meu véu vai cair!"- e traz as definições de Rui para a moda, o que irá chamar "a minha verdade".

A biografia de Rui, somada a outras fontes como reportagens em jornais e revistas e entrevistas, foram os norteadores do texto de minha dissertação onde analiso, justamente, a transformação de Flavio em Rui ou "a invenção de Rui Spohr" e a consolidação de seu estilo- espécie de identidade têxtil de sua assinatura- o qual chama "a sofisticada originalidade do simples."

A partir do conceito de identidade de Stuart Hall onde esta se forma através de processos inconscientes, sempre incompleta, "em processo", ao analisar a biografia de Rui fica claro o quanto a memória é elemento constituinte de um sentimento de identidade, alicerçando, de certa forma, sua mobilidade. Neste sentido, cabem as ideias de Michel Pollak onde "a imagem que uma pessoa adquire ao longo da vida referente a ela própria, a imagem que ela constrói e apresenta aos outros e a si própria, para acreditar na sua própria representação, mas também para ser percebida da maneira como quer ser percebida pelos outros" (POLLAK, 1992, p.5). Dessa forma, a construção da identidade se dá por meio de uma negociação onde referências reais ou inventadas podem carregar as noções de passado, tradição e memória na construção ou na atualização de uma representação em que códigos e valores sejam partilhados por um coletivo, mas também estabeleçam suas diferenças, seus limites em relação ao outro.

O capítulo das "Memórias..." dedicado à Paris dá conta da transformação que se iniciara ainda em Novo Hamburgo, quando, ao estrear como jornalista em um jornal local, assinou o texto como Rui porque se preocupava com a reação da família. E 1949 organizou seu primeiro desfile, inspirado no que via no cinema de Hollywood e em 1951, com o dinheiro da herança do pai, zarpou em um navio para a França, aos 22 anos.

Estudou na École de la Chambre Syndicalle de la Couture Parisienne e na École Guerre-Lavigne, obtendo a mesma formação de grandes nomes da moda internacional do século XX como Yves SaintLaurent e Karl Lagerfeld e foi assistente de Jean Barthet - um importante chapeleiro da época. Vivendo na cidade que, à época, era "um mito, uma coisa longínqua, um sonho que ninguém alcançava"12, as memórias construídas na capital francesa tornaram-se fatores importantes nesse processo de reconstrução de si- identidade "em processo que aos poucos constrói também uma nova imagem.

Ao se estabelecer em Porto Alegre, Rui invadiu o espaço da moda feminina, até então também dominado por mulheres. Mary Steigleder, chapeleira e modista influente, que seguia a corrente de cópia

\footnotetext{
${ }^{11}$ IDEM.

${ }^{12}$ Foi dessa forma que Rui Spohr definiu Paris e a representatividade de sua permanência na cidade no início da década de 1950, em entrevista concedida em dezembro de 2012.
} 
de moldes franceses, liderada ela Casa Canadá, de Menna Fiala, no Rio de Janeiro. Para "abalar as estruturas" de Mary- a quem refere-se em suas "Memórias..." como madame " Cuja Dita"- Rui passou a também a publicar crônicas de moda no "A Última Hora", jornal local. Os textos sempre são acompanhados de croquis, muitas vezes suas versões para as tendências da época. Ou seja, à sua imagem de recém-chegado de Paris incorpora-se também a ideia de um "civilizador", que domina os códigos e processos da moda e através dele propõe modelos autorais.

Logo no início da carreira, encontra Dóris, sua primeira assistente que se tornou sua esposa, companheira de vida, de trabalho e também sua melhor modelo.

O reconhecimento nacional veio na década de 1960, quando Rui passou a integrar o time de costureiros da Rhodia ${ }^{13}$. Nesse momento, assumiu aspectos da cultura regional como forma de demarcar seu estio que passa a ser representativo de uma identidade relacional ${ }^{14}$, ou seja, além de trazer para o local elementos que se articulam à moda de Paris, projeta os valores regionais.

Em tempos globalizados, em que a moda já não constitui mais segredo algum e grupos multinacionais exercem impacto poderoso sobre a sua forma de consumo, a busca por uma identidade têxtil revestida de valores culturais, carregados de memórias e de simbolismos individuais e coletivos, mostra-se mecanismo importante na delimitação de espaços.

Em sua trajetória, é possível afirmar que Rui abriu espaço para uma moda profissionalizada, inserida em seu contexto histórico e social, tornando-se dele também testemunho. Em função de sua atuação longeva, tornou-se referência não apenas em relação ao estilo, mas também ao fazer: recebeu em seu atelier inúmeros aprendizes, estagiários- estendendo sua vocação pedagógica para além dos conselhos do jornal-, assim como desenvolveu parceria com artesãos, tecelagens, demais empresários, ajudando a dar visibilidade a iniciativas locais ${ }^{15}$.Sem dúvidas, seu maior reconhecimento se deu em função das roupas sob medida, vestiu gerações de mulheres em momentos socialmente importantes como baile de debutantes e casamentos. Através desses eventos, das dinâmicas de sociabilidade, impõe um estilo, mas é constantemente reorientado por valores que se (re)articulam, se modificam, dentro da sociedade onde atua. ${ }^{16}$

\section{RETRATOS DO COSTUREIRO}

Não demorou muito para que a nudez de Rui virasse o prato principal das conversas em Porto Alegre. 'Ele vai posar pelado e sem aliança', ouvia-se de um lado. 'Será nu frontal', rebatiam de outro. ${ }^{17}$

O comentário da jornalista Mariana Kalil sobre o retrato polêmico que seria revelado na exposição Rui, estilo em fotos ajudam a situar a posição do costureiro na tradicional Porto Alegre. Se no conto

\footnotetext{
${ }^{13}$ A indústria química francesa promovia seus fios sintéticos no Brasil por meio de desfiles-show, editoriais e coleções de moda, numa estratégia desenvolvida por Lívio Rangan (1933-1984), visionário gerente de publicidade da empresa. Os desfilesshow, realizados entre 1960 e 1970, pareciam mais espetáculos e reuniam profissionais do teatro, da dança, música e das artes visuais. Os desfiles da Rodhia são alvo de estudo da historiadora Maria Claudia Bonadio, autora da publicação.

${ }^{14}$ Parte-se da ideia do "pensamento relacional" de Pierre Bourdieu. Para Bourdieu, o indivíduo (ou ainda a sua obra artística) só existe dentro de uma rede de relações visíveis ou invisíveis, que definem uma posição social, ou seja, uma posição de cada um em relação aos outros.

15 Ao expor as peças guardadas no acervo, Dóris Spohr gosta de comentar as parcerias desenvolvidas com artesãos locais: trabalhos em lã, em tear, pintura em seda, tingimento de rendas, botões personalizados, são algumas das técnicas regularmente empregadas nos modelos de Rui.

${ }^{16}$ Um exemplo que poderia demonstrar essa reorganização de valores seria o do vestido de noiva. Rui acha as festas de casamento dos dias de hoje um evento exagerado, "onde tudo se organiza em função da noiva", diz que a festa, a comemoração tornou-se mais importante do que a cerimônia de casamento. Acha que, muitas noivas deixam de o procurar pois não costuma fazer modelos tomara-que-caia, segue vestindo as noivas tendo em mente o ato religioso.

${ }^{17}$ KALIL, Mariana. Op.cit.
} 
infantil ${ }^{18} \mathrm{o}$ rei, vaidoso finge estar vestido com o tecido que só os inteligentes são capaz de ver, quando na verdade está nu, neste caso costureiro aceitou prontamente despir-se. Tão chocante quanto seu corpo nu, a ausência da aliança. Negar as roupas, por um lado, é negar o decoro, a etiqueta, poderia soar desdenhoso até mesmo ao seu ofício que é justamente o de vestir os corpos, causa confusão pois deixa dúvidas de que quem se mostra é Rui ou Flávio- ou ambos. A ausência da aliança abre mão de sua reputação de homem casado, pode pôr em jogo sua sexualidade e, o mais importante, simbolizaria também a ausência de Dóris.

Se o criador de moda é um colecionador de imagens, que evoca, reorganiza, rememora a cada ao traçar cada novo vestido, ao planejar cada coleção, atividade interessante é essa de olhar para as imagens que formam o próprio costureiro. No caso de Rui, pude ter acesso privilegiado aos álbuns de viagens, de família - quando ainda existia apenas o Flavio. A imagem que se constrói é feita de nuances sutis, gestos que reaparecem como uma espécie de herança pois como sugere Aby Warburg "a criação consciente da distância entre si e o mundo exterior pode ser designada como o ato básico da civilização humana" (WARBURG, 2015, p.363). Ou seja, a sublimação dos instintos, demonstrada por Freud, que se salienta na evolução cultural através do que poderia ser compreendido como uma atividade psíquica mais elevada, também poderia ser encarada como fator identitário, por acabar motivando a construção de uma imagem de si e que também se apresenta aos outros. Das imagens de Rui, fica evidente a relação com o corpo, tanto o seu corpo quanto o corpo feminino que irá vestir.

As imagens selecionadas para essa análise se deram, especialmente, pela sua circulação: são imagens que estiveram em jornais, revistas, foram veiculadas em mídias sociais, estão na internet ou ainda foram mostradas em vídeos e palestras. O acesso privilegiado ao acervo de Rui Spohr, por outro lado, permitiu o acesso a imagens que poderiam ser consideradas complementares, ou seja, "provas" de fotografias, demais imagens que formam séries, álbuns de família, anotações que acompanham os registros.

Como sugere o filósofo Didie-Huberman, estar diante da imagem é como estar diante do tempo, diante do vão de uma porta aberta, onde o presente e o passado não cessam de se reconfigurar pois ela proporciona um encontro entre o tempo e a memória. Se a "memória tem mais presente e mais futuro que o ser que a olha" (DIDI-HUBERMAN, 2015, p.16), as fotografias escolhidas são testemunhos definitivos- uma vez que, provavelmente, sobreviverão a Rui. Susan Sontang estabelece uma abordagem que leva a pensar na fotografia como uma construção-- sem deixar de lado seus atributos de poder. A autora observa que "uma foto não é apenas semelhante ao seu tema, uma homenagem ao seu tema. Ela é uma parte e uma extensão daquele tema; e um meio poderoso de adquiri-lo, de ganhar controle sobre ele" (SONTANG, 2011, p.172).

Desta forma, as fotografias selecionadas além de construídas circularam de maneira selecionada, de forma a integrar a imagem de Rui Spohr, representativa de sua atuação em um campo social e simbólico, relacionado ao universo da moda e suas dinâmicas.

\section{O CORPO DA MODA}

A moda é seu ofício e também sua expressão, domina seus códigos, traduz as tendências - e não apenas as copia - sagrado por sua vivência na capital parisiense e seu reconhecimento nacional.

Qual seria o corpo da moda? Aquele que é modelado, (re)velado, estudado, cuidado, exigido. Dentro do atelier de costura, o corpo da moda é representado pelo manequim ou busto de costura. Com

${ }^{18}$ Evoco aqui o conto infantil “A roupa nova do rei”, escrito por Hans Christian Andersen, publicado em 1837. 
formas que imitam as reais, será utilizado para o estudo dos modelos- a preparação do toile, a verificação do caimento correto, a correção de possíveis defeitos e, finalmente, a exibição da roupa pronta. O manequim encena o corpo, antecipa-o, serve de suporte da roupa enquanto essa ainda não está pronta para receber o corpo real e integrar-se aos seus gestos. E mesmo quando substituído pelo corpo da modelo, segue evocando uma possibilidade, uma encenação.

Nas fotografias souvenir, Rui posa no Trocadèro, com a torre Eiffel ao fundo, faz o que hoje, nos dias de hoje, poderia ser considerado uma selfie em frente as lojas de costureiros famosos à época, como Jacques Fath e Christian Dior, dos motivadores a partir para Paris estudar moda, afinal, era Dior quem vestia Evita, a primeira dama argentina, que acompanhava nas páginas da O Cruzeiro e cujos vestidos tentava imaginar enquanto cortava couro na fábrica de calçados do pai.

O quartinho no 1,80X2m, no sexto andar sans ascenseur onde morou também está lá registrado. E é nesse espaço que fotografa uma amiga, em pose estática, como a de um manequim de vitrine, com o rosto quase coberto por um chapéu- criação sua- corpo escondido por um pedaço de tecido-que ainda não é roupa, apenas uma sugestão- que parece se ligar à janela, que faz às vezes de moldura.

Figura 1 - Mulher usando chapéu - 1953/1954

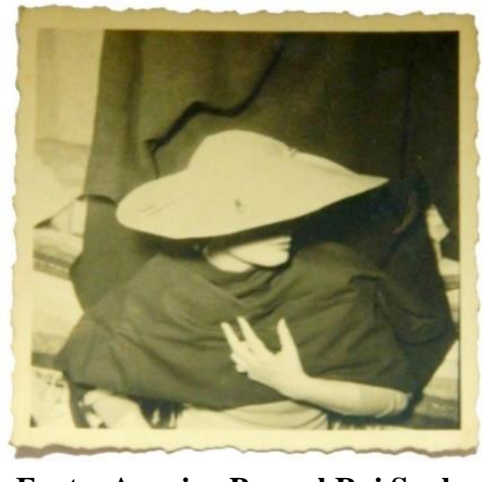

Fonte: Arquivo Pessoal Rui Spohr

Às vésperas do primeiro desfile, ainda em Novo Hamburgo, Rui se faz fotografar no chão, fita métrica no pescoço, tesoura, tecido, um vestido cuidadosamente jogado sobre o sofá - prestes a vestir o corpo, que ainda é ausente - como se estivesse prestes a tirar do papel os modelos por ele desenhados, onde se podem ver saias amplas - possivelmente a já citada influência de Dior através de Evita.

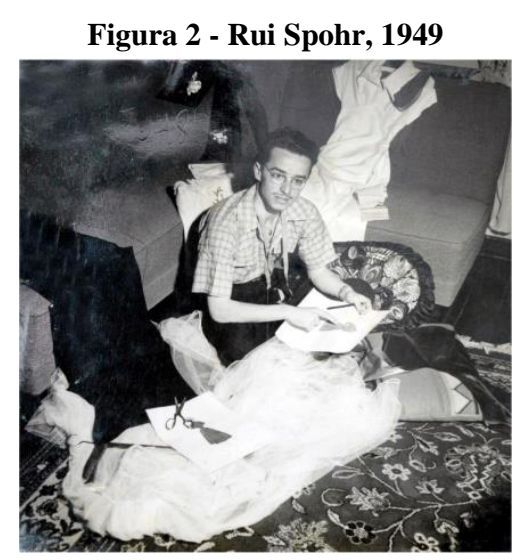

Fonte: Arquivo Pessoal Rui Spohr

Ao instalar-se em Porto Alegre, a imagem é a do costureiro em ação: sentado, papel apoiado sobre a perna para esboçar o modelo, o manequim aparece ao fundo, envolto por uma grande faixa de tecido, 
prestes a se tornar vestido. Reforça-se a ideia de criador: para o trabalho solene, veste-se de terno e gravata. Se talento reside não apenas no desenho, mas na capacidade em materializar a ideia.

Figura 3 - Rui Spohr - 1955

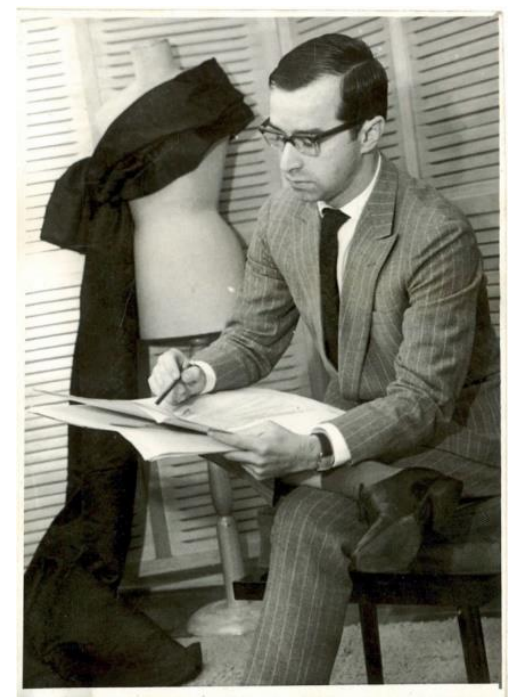

Fonte: Arquivo Pessoal Rui Spohr

Nos anos 1970, o manequim reaparece. Se na década de 1960 Rui se consagra nacionalmente ao participar dos desfiles da Rhodia, o momento é de consolidação, com a transferência de endereço para a Rua Miguel Tostes- onde permaneceu durante mais de 40 anos- e dedicação ao prêt-à-porter.

Rui aparece em roupas claras, descalço, numa atitude entre a descontração e a intimidade. Ao fundo, a máquina de costura antiga, o manequim de vitrine que imita uma mulher sentada e, ao fundo, o busto de costura.

Figura 4 - Rui Spohr - 1972

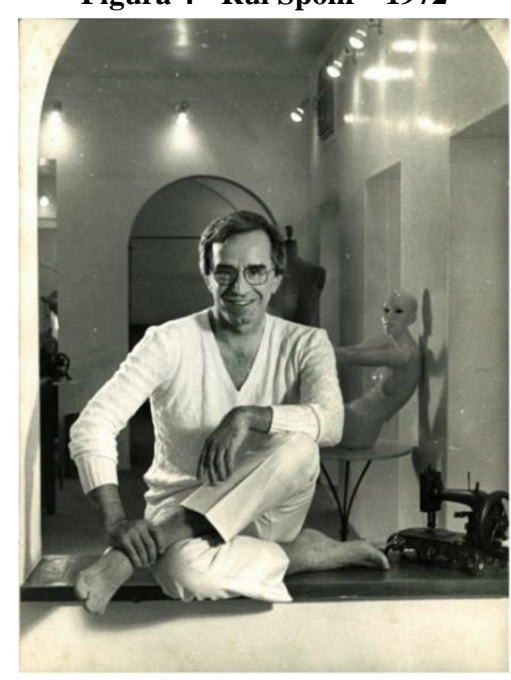

Fonte: Arquivo Pessoal Rui Spohr

Na mesma série, Rui coloca-se ao chão, ao lado do manequim de vitrine que parece olhar para o alto, traz apenas um sapato calçado no pé esquerdo. $\mathrm{O}$ manequim ganha algum sentido de sacralidade pois na imagem, a visão que se forma é a de uma espécie de nicho, reforçado pela parede em arco onde Rui se apóia. Ao centro, o manequim, envolto por uma pele de raposa. Adereço, por muito tempo, reservado aos reis, a nobreza da pele reside em sua escassez, ao mesmo tempo em que evoca algo de 
primitivo, abrigo tomado dos animais porque a pele humana não seria suficiente para protegê-lo, conquista da natureza e, portanto, dos próprios instintos.

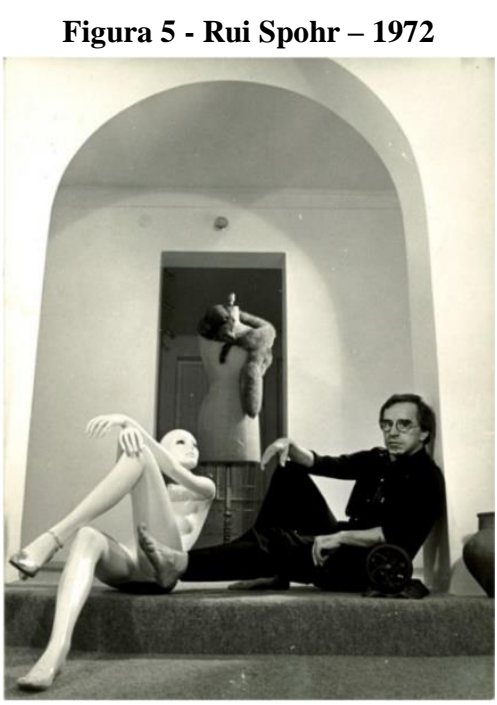

Fonte: Arquivo Pessoal Rui Spohr

Há ainda uma série onde Rui abraça o mesmo manequim, então forrado com tecido colorido. A pose foi repetida em 2015: Rui abraça o manequim às vésperas de completar 60 anos de carreira, no sótão da casa da Rua Miguel Tostes, espaço onde conservava seu acervo pessoal. ${ }^{19}$

Figura 6 - Rui Spohr - 1972

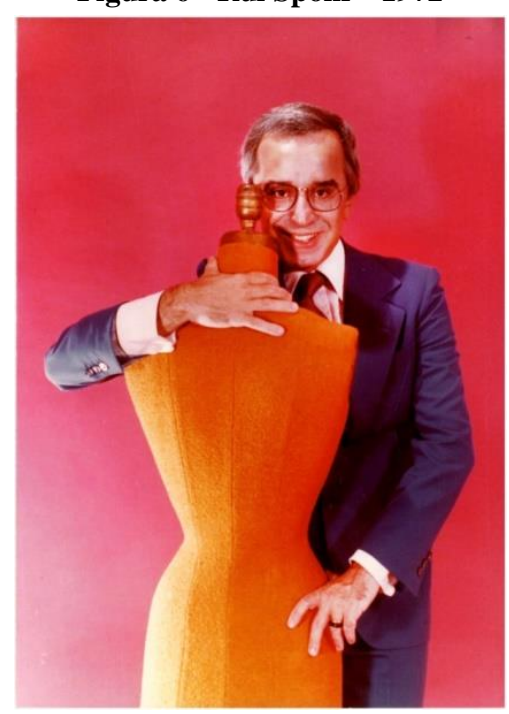

Fonte: Arquivo Pessoal Rui Spohr

${ }^{19}$ A casa foi demolida em dezembro de 2015. Com isso, as atividades foram transferidas para a casa imediatamente ao lado, um pouco menor. $\mathrm{O}$ acervo encontra-se guardado em uma sala comercial, especialmente alugada, no mesmo quarteirão. 


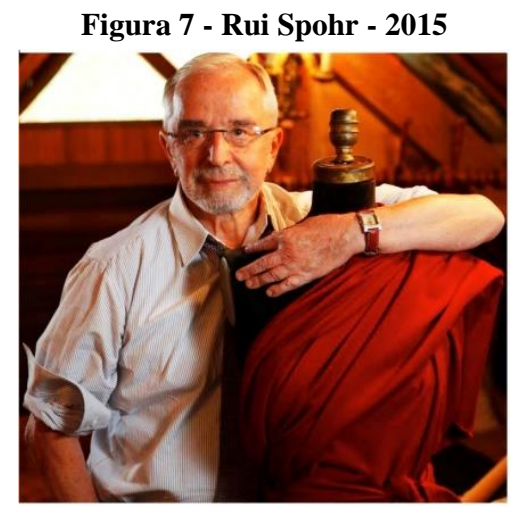

Fonte: Caderno Donna/Jornal Zero Hora

Mas, a imagem mais marcante e é preto e branco, feita pelo fotógrafo Sergio Axelrud é aquela onde Rui, olhar protegido pelos óculos, abraça o manequim que esconde a sua nudez.

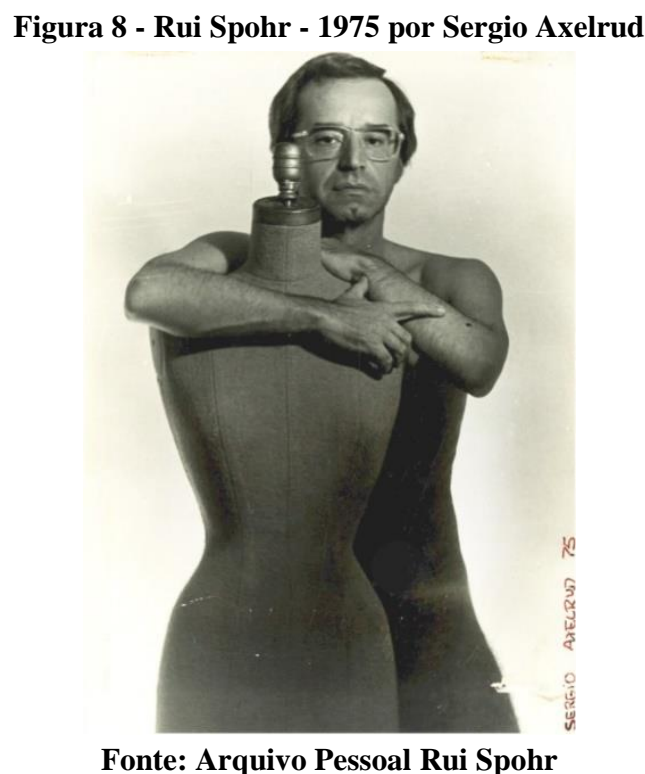

\section{ALGUMAS CONSIDERAÇÕES}

A moda como fenômeno que se faz a partir de imagens e delas se reinventa, num constante movimento, articula múltiplos tempos, reconfigura-se a cada novo desenho, a cada nova coleção, a cada imagem construída a partir de si mesma.

Nesse processo, parece haver uma estratégia sobrevivente que, semelhante àquela do rei, constitui-se em voltar para o olhar do outro e, com ele, adquirir relação de interdependência. Na relação de consumo que se estabelece, isso seria equivalente a estratégia de Worth de voltar-se à uma clientela internacional- não sem antes permitir que seus modelos também fossem copiados, de maneira literal, dos jornais e revistas. Estratégia semelhante a desenvolvida por Christian Dior, que associa seus modelos ao imaginário de Paris, tem seu modelo mais icônico batizado new look em território americano e, por sua vez, estabelece uma série de licenciamentos, a fim diversificar seus produtos. Ainda antes de Dior, e com estilo bastante distinto, o vestido preto modelo chemise de Gabrielle Chanel também havia sido aclamado pela imprensa americana: chamado "Ford Chanel", pois, assim como o modelo " $T$ " da empresa de automóveis, ele seria disponível a todas as mulheres, de todas as classes sociais.

Sobrevivente também é o estilo associado ao costureiro: mesmo quando da ausência do criador, suas memórias passam a compor o imaginário da maison, da marca; seus arquivos atualizam-se 
infinitamente, passíveis de receberem o olhar de novos criadores- como acontece do contemporâneo, a exemplo de Karl Lagerfeld que fundiu sua visão a de Chanel, e através dela reveste o corpo de LilyRose, numa promessa de continuidade, cheia de juventude.

No caso de Rui, mesmo que falem as imagens, ainda restam perguntas. Porém, o desejo de estar a frente do tempo, ser "cabeça aberta", permanecer- ou ser eterno como o rei -se manifesta em detalhes de construção da imagem, como o relógio que nunca sai do pulso e os óculos, que garantem o olhar apurado, assim como o abraço envolvente no manequim que representa o corpo feminino -o qual conhece bem a forma- que irá vestir; corpo que também que o protege, numa relação de (quase) intimidade.

\section{REFERÊNCIAS}

BAUDELAIRE. Charles. O Pintor da vida moderna. Trad. Tommaz Tadeu. Belo Horizonte: Ed. Auntêntica, 2010.

BENJAMIN, Walter. Obras Escolhidas III. Rua de mão única. Trad. Rubens Rodrigues Torres Filho e José Carlos Martins Barbosa. São Paulo: Ed Brasiliense, 2011.

BURKE, Peter. A fabricação do rei. A construção da imagem pública de Luís XIV. Trad Maria Luiza X. de A. Borges. Rio de Janeiro: Ed. Jorge Zahar editor, 1994.

CRANE. Diana. A moda e seu papel social, classe gênero e identidade das roupas. Trad. Cristina Coimbra. São Paulo: Ed. Senac, 2009.

DIDI-HUBERMAN, Georges. Diante do Tempo. História da arte e anacronismo das imagens.

O que vemos, o que nos olha. Trad. Paulo Neves. São Paulo: Editora 34, 2014.

ELIAS. Norbert. A Sociedade de corte. Trad. Pedro Sussekind. Rio de Janeiro: Ed. Zahar, 2001. . O processo civilizador. Vol.1: Uma história dos costumes. Rio de Janeiro: Ed. Zahar, 2011.

FLUGEL, J. C. Sobre o valor afetivo das roupas. Revista Psyché, São Paulo, ano XIII, n. 22 p.13-26. Jan./jun., 2008.

FREUD, Sigmund. Obras Completas volume 18. O mal-estar na civilização, novas conferências introdutórias e outros textos (1930-1936). Trad. Paulo César de Souza. São Paulo: Ed. Companhia das Letras, 2010.

LIPOVETSKY, Gilles, O Império do efêmero. Trad. Maria Lúcia Machado. São Paulo: Ed. Companhia de bolso, 2009.

MONNEYRON, Fréderic. La frivolité essentielle. Paris: Ed. Puf, 2008.

PARESYS, Isabelle. La cour de France, fabrique de normes vestimentaires à l'époque moderne. IN: La Fabrique de la norme. Veronique Beaulande-Barraud, Julie Claustre et Elza Marmursztejn. Presses Universiteraires de Rennes, 2012.

POLLAK. Michael. Memória e identidade social. Estudos Históricos, Rio de Janeiro, vol. 5, n. 10, 1992.

WARBURG, Aby. Histórias de fantasmas para gente grande. Escritos, esboços, conferências. São Paulo: Ed. Companhia das Letras, 2015. 
RUBIO, Lourdes Cerilo. La moda moderna. Génesis de um arte nuevo. Madrid: Ed. Siruela, 2010.

SIMMEL, Georg. Filosofia da moda e outros escritos. Lisboa: Ed. Texto e Grafia, 2008.

SONTANG, Susan. Sobre a Fotografia. São Paulo: Ed. Companhia das Letras, 2011.

SPOHR, Rui. VIÉGAS-FARIA, Beatriz. Memórias Alinhavadas. Porto Alegre: Ed. Artes e Oficios, 1997.

STALYBRASS, Peter. O casaco de Marx. Roupas, memórias, dor. TRAD. Tomaz Tadeu da Silva. Belo Horizonte: Ed. Autêntica, 2004.

SVENDSEN, Lars. Moda: uma filosofia. Rio de Janeiro: Ed. Zahar, 2010.

TÈTARD-VITTU, Françoise. La naissance du couturier et du modeliste IN: Au paradis des dames. Catálogo de exposiçao. Paris Musées, 1992.

TROY, Nancy. Couture Culture. A Study in modern art and fashion. The MIT press. Massachustes, 2003.

VEBLEN, Thorstein. Os pensadores: Veblen. Rio de Janeiro: Ed. Abril Cultural, 1980. 